\title{
Outcome of heart-lung and bilateral sequential lung transplantation for cystic fibrosis: a UK national study
}

\author{
J.S. Ganesh, C.A. Rogers, R.S. Bonser and N.R. Banner, \\ on behalf of the steering group of the UK Cardiothoracic Transplant Audit
}

ABSTRACT: Cystic fibrosis (CF) patients requiring transplantation for respiratory failure may undergo either heart-lung (HLT) or bilateral sequential lung (BSLT) transplantation. The choice of operation varies between surgeons, centres and countries.

The current authors investigated whether operation type influenced outcome in adult CF patients transplanted in the UK between July 1995 and June 2002. Propensity scores for receipt of BSLT versus HLT were derived using logistic regression. Cox regression was used to compare survival.

In total, 88 BSLTs and 93 HLTs were identified. Patient characteristics were similar overall, but HLT recipients were more likely to be on long-term oxygen therapy and to have had prior resuscitation. There were 72 deaths (29 BSLT and $43 \mathrm{HLT}$ ) within 4 yrs. There was a trend towards higher unadjusted survival following BSLT, but, after adjustment, no difference was found (hazard ratio $=0.77 ; 95 \%$ confidence interval $0.29-2.06$ ). Time to the first rejection episode and infection rates were also similar. A total of $82 \%$ of hearts from HLT recipients were used as domino heart transplants.

In conclusion, after adjusting for comorbidity, donor factors and ischaemia time, it was found that heart-lung and bilateral sequential lung transplantation achieved a similar outcome. The use of domino heart transplantation ameliorated the impact of heart-lung transplantation on total organ availability.

KEYWORDS: Adults, cystic fibrosis, lung transplantation, outcomes, survival

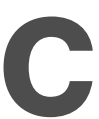
ystic fibrosis (CF) is the most common, life-threatening, inherited disease in Caucasians. It affects 7,500 patients at any time in the UK [1] and $\sim 30,000$ patients in the USA, with 10 million Americans being symptomless carriers of the defective CF gene [2]. Despite the multisystem nature of the disease, pulmonary complications are the cause of death in $>95 \%$ of CF patients [3]. Currently, transplantation is the only effective treatment for $\mathrm{CF}$ patients with respiratory failure [4-6] and constitutes a third of the bilateral sequential lung transplantation (BSLT) procedures in children and adults reported to the International Society for Heart and Lung Transplantation [7, 8]. CF patients are the largest single group of patients referred for transplantation with end-stage suppurative lung disease [9]. Currently, as many as $40-50 \%$ of CF patients die on the waiting list due to a paucity in the supply of donor lungs [6].

For editorial comments see page 947.
Survival benefits and pulmonary function improvement for CF patients have been reported separately after heart-lung transplantation (HLT) [10-12] and BSLT [13, 14]. Initial results for pulmonary transplantation from the UK national audit have been reported in a preliminary form [15]. In this study, the current authors have investigated whether the type of operation (BSLT or HLT) affects the outcome following transplantation for $\mathrm{CF}$, using the UK national audit database.

\section{METHODS}

The UK Cardiothoracic Transplant Audit is a national prospective cohort study that has been collecting data since April 1995 on all intrathoracic transplantation procedures in the UK. The audit collects data when patients are registered on the national waiting list for heart and/or lung transplantation, at the time of transplantation and at selected (90 days and yearly thereafter) follow-up periods.

\section{AFFILIATIONS}

UK Cardiothoracic Transplant Audit, Clinical Effectiveness Unit, The Royal College of Surgeons of England,

London, UK.

\section{CORRESPONDENCE}

N.R. Banner

Cardiothoracic Transplant Unit

Royal Brompton \& Harefield NHS

Trust

Harefield Hospita

Hill End Road

Harefield

Middlesex UB9 6JH

UK

Fax: 441895828556

E-mail: n.banner@rbh.nthames.

nhs.uk

Received:

June 172004

Accepted after revision:

February 242005

SUPPORT STATEMENT

This study was carried out with the support of funding from the Dept of Health, London, UK. 
In the current study, adult CF patients (aged $\geqslant 16 \mathrm{yrs)}$ undergoing first-time, isolated lung transplantation or HLT from cadaveric donors between July 1995 and June 2002 were analysed retrospectively. Seven en bloc double-lung transplants carried out during this period were excluded.

Survival to 4 yrs was the primary end-point of the study. Surviving patients were censored at their last reported followup or at 4 yrs (whichever was earlier). Secondary outcomes were time to the first treated rejection episode, number of treated infection episodes, change in forced expiratory volume in one second (FEV1) and use of the domino (HLT) or donor heart (BSLT).

Donor and pre-transplant recipient characteristics were compared using the Chi-squared/Fisher's exact tests (categorical data) or the Kruskal-Wallis test (continuous variables). Fisher's exact test was chosen in preference to the Chi-squared test when $>20 \%$ of the expected frequencies were less than five.

All analyses were adjusted for possible confounding variables. Differences in recipient covariates were summarised using propensity scores $[16,17]$. Derived using logistic regression, the propensity score is the probability of receiving HLT (rather than a BSLT), which is conditional on the recipient's risk profile. Propensity-score centiles were used to adjust the treatment effect (HLT versus BSLT) for differences in recipient covariates not accounted for by other variables included in the outcome analysis. Propensity-score quintiles have been shown to reduce $80 \%$ of the bias in the variables used to derive the score [16]. Limiting the number of bias-reducing covariates included in the outcome analyses in this way is particularly relevant when the study is small and events are few. Recipient variables included in the propensity score were as follows: age (grouped as 16-22 yrs, 23-30 yrs, and >30 yrs); sex; body mass index (BMI; grouped as $<17.5,17.6-19.3$, and $>19.4 \mathrm{~kg} \cdot \mathrm{m}^{-2}$ ); difference in the recipient's weight at transplant and the ideal weight for age and sex (three categories; a difference of $>15 \mathrm{~kg}$, 10-15-kg difference, and $<10-\mathrm{kg}$ difference) [18]; percentage predicted FEV1 and forced vital capacity (FVC; $<30 \%$ compared with $>30 \%$ predicted for FEV1 and $<40 \%$ compared with $>40 \%$ predicted for FVC); history of domiciliary oxygen support; history of previous thoracotomy; diabetes; creatinine clearance $\left(<75 \mathrm{~mL} \cdot \mathrm{min}^{-1}, 75-100 \mathrm{~mL} \cdot \mathrm{min}^{-1},>100 \mathrm{~mL} \cdot \mathrm{min}^{-1}\right)$; bilirubin; infection; and admission to hospital prior to transplantation. History of prior resuscitation and ventilation prior to transplantation were not included in the propensityscore calculation as all the events occurred in the HLT group. The ability of the model to discriminate between BSLT and HLT was evaluated using the area under the receiveroperating characteristic (ROC) curve, and the model fit was assessed using the Hosmer-Lemeshow Chi-squared test.

Cox regression [19] was used to compare survival between the two groups, with and without adjustment for centre volume (six categories; three centre categories with $>40$ transplants each, two centre categories with 10-15 procedures each and a sixth category of two centres who had performed less than five transplants each). The analyses were adjusted for the following: propensity-score quartiles; history of prior resuscitation; home oxygen support; ventilation prior to transplantation; diabetic status; FEV1 and ideal weight groups (as described previously) in the recipient; donor variables; year of transplant (in two eras; July 1995-June 1999 and July 1999-June 2002); and time from listing to transplant (in five groups; $\leqslant 30$ days, $31-90$ days, 91-180 days, 181-365 days, and $>365$ days). The following donor variables were included in the model: donor age (grouped as $<22$ yrs, 23-34 yrs, and $>35 \mathrm{yrs}$ ); sex; cytomegalovirus (CMV) mismatch (CMV-positive donor, CMV-negative recipient); donor past history (including history of smoking, alcohol and/or drug abuse); use of inotropic support in the donor and ischaemia time (grouped as $<3 \mathrm{~h}, 3$ $4 \mathrm{~h}$, and $>4 \mathrm{~h}$ ). Ischaemia time for BSLT was taken as the time from donor cross-clamp to reperfusion of the first lung. Missing ischaemia times were imputed, using partial data, where available. For example, if the time from organ arrival to the reperfusion was known, but the cross-clamp time was missing, the median travel time from the donor to recipient hospital was added to the recorded time.

Time to the first rejection episode was also compared using Cox regression, after adjustment for propensity-score quartiles and CMV mismatch. The proportional-hazards assumption was checked for all survival models fitted.

Post-transplant infection rates between the two groups were compared using negative binomial regression after adjusting for propensity-score quartiles, CMV mismatch and length of follow-up. Model fit was assessed using the Chi-squared test.

Waiting time to transplant and waiting-list mortality were compared in the cohort of adult CF patients ( $\geqslant 16 \mathrm{yrs}$ ) registered on the waiting list for either HLT or BSLT between July 1995 and June 2002 using the Kaplan-Meier method.

\section{RESULTS}

A total of 181 (88 BSLT and 93 HLT) first-time adult (aged $\geqslant 16$ yrs) CF patients undergoing transplantation between July 1995 and June 2002 in seven centres across the UK were studied (fig. 1).

In the UK, HLT was the dominant procedure until 2000, but, since then, BSLT has become more common $(p=0.03$, Chisquared test for trend).

Donor and recipient characteristics were similar across the two groups of CF patients (table 1). The only differences were

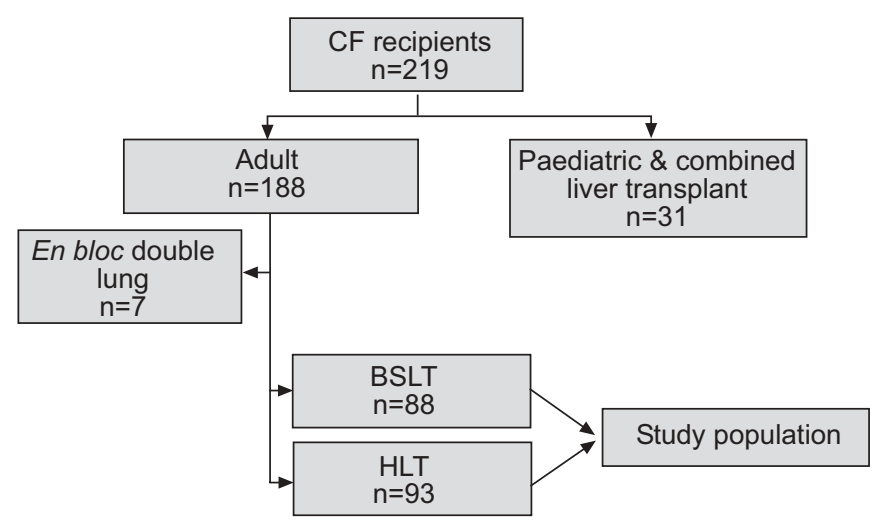

FIGURE 1. Denomination of the study population in cystic fibrosis (CF) patients undergoing transplant from the total UK CF transplant population. BSLT: bilateral sequential lung transplantation; HLT: heart-lung transplantation. 


\begin{tabular}{|c|c|c|c|}
\hline $\begin{array}{ll}\text { TABLE } 1 & \text { Pre-transplant } \\
& \text { cystic fibrosis }\end{array}$ & $\begin{array}{l}\text { characteristics } \\
\text { (CF) and orga }\end{array}$ & $\begin{array}{l}\text { of patients w } \\
\text { n donors }\end{array}$ & \\
\hline Characteristics & BSLT & HLT & p-value \\
\hline \multicolumn{4}{|l|}{ Patients with CF } \\
\hline Subjects n & 88 & 93 & \\
\hline Age yrs & $24(20-28)$ & $26(21-31)$ & 0.1 \\
\hline Males & $48(55)$ & $54(58)$ & 0.6 \\
\hline Height $\mathrm{cm}$ & $164.5(159-171)$ & $166(158-173)$ & 0.5 \\
\hline Weight kg & $50(44-56)$ & $50(43-57)$ & 0.8 \\
\hline BMI & $18(17-20)$ & $18(17-20)$ & 0.5 \\
\hline Previous thoracotomy & $5(6)$ & $6(6)$ & 0.8 \\
\hline Previous resuscitation ${ }^{\#}$ & 0 & $8(9)$ & 0.004 \\
\hline Diabetes & $22(25)$ & $35(38)$ & 0.07 \\
\hline Prednisolone given ${ }^{\#}$ & $31(35)$ & $43(46)$ & 0.1 \\
\hline Bilirubin $\mu \mathrm{mol} \cdot \mathrm{L}^{-1}$ & $7(5-9)$ & $7(5-11)$ & 0.2 \\
\hline Creatinine $\mu \mathrm{mol} \cdot \mathrm{L}^{-1}$ & $80(66-89)$ & $73(55-94)$ & 0.3 \\
\hline Creatinine clearance ${ }^{\#} \mathrm{~mL} \cdot \mathrm{min}^{-1}$ & $86(76-100)$ & $96(77-122)$ & 0.03 \\
\hline Home oxygen $n$ & $49(56)$ & $74(80)$ & 0.001 \\
\hline \multicolumn{4}{|l|}{ FEV 1} \\
\hline$L^{\#}$ & $0.8(0.65-0.91)$ & $0.7(0.55-0.95)$ & 0.3 \\
\hline$\%$ pred $^{\#}$ & $20(16-25)$ & $20(16-25)$ & 0.4 \\
\hline$<30 \%$ pred $n$ & $79(90)$ & $82(88)$ & 0.7 \\
\hline$>30 \%$ pred $n$ & $9(10)$ & $11(12)$ & \\
\hline \multicolumn{4}{|l|}{ FVC } \\
\hline$L^{\#}$ & $1.55(1.2-2)$ & $1.5(1.1-2.1)$ & 0.6 \\
\hline$\%$ pred $^{\#}$ & $35(29-47)$ & $34(26-45)$ & 0.6 \\
\hline$<40 \%$ pred $n$ & $54(61)$ & $60(65)$ & 0.7 \\
\hline$>40 \%$ pred $n$ & $34(39)$ & $33(35)$ & \\
\hline In-hospital at transplant $\mathrm{n}$ & $15(17)$ & $26(28)$ & 0.08 \\
\hline Ventilation at transplant $\mathrm{n}$ & 0 & $3(3)$ & 0.2 \\
\hline Pre-operation infection ${ }^{\#} \mathrm{n}$ & $68(79)$ & $73(79)$ & 0.9 \\
\hline \multicolumn{4}{|l|}{ Donor characteristics } \\
\hline Age yrs & $29(21-39)$ & $28(16-37)$ & 0.2 \\
\hline Males $\mathrm{n}$ & $38(43)$ & $45(48)$ & 0.5 \\
\hline Health status" & $23(26)$ & $19(20)$ & 0.4 \\
\hline Inotropes n & $19(22)$ & $14(15)$ & 0.3 \\
\hline Height $\mathrm{cm}$ & $166(160-175)$ & $165(160-172)$ & 0.6 \\
\hline Weight kg & $65(55-70)$ & $63(55-70)$ & 0.7 \\
\hline BMI & $22.5(20-24)$ & $22.5(20-24)$ & 1.0 \\
\hline CMV positive $n$ & $35(41)$ & $38(41)$ & 1.0 \\
\hline CMV mismatch $\mathrm{n}$ & $25(28)$ & $27(29)$ & 0.9 \\
\hline Ischaemia time min & $309(260-360)$ & $215(182-268)$ & $<0.001$ \\
\hline Blood-group mismatch $n$ & $12(14)$ & $10(11)$ & 0.6 \\
\hline
\end{tabular}

Data are presented as $n, n(\%)$ and median (interquartile range), unless otherwise stated. BSLT: bilateral sequential lung transplantation; HLT: heartlung transplantation; BMI: body mass index; FEV1: forced expiratory volume in one second; \% pred: \% predicted; FVC: forced vital capacity; CMV: cytomegalovirus. ${ }^{\#}:<5 \%$ missing values; ": includes alcohol, smoke or drug abuse.

history of resuscitation for a sudden near-death episode, use of ambulatory oxygen support at home, creatinine clearance and ischaemia time. The numbers of patients who had suffered near-death episode(s) $(p=0.004)$ and required long-term domiciliary oxygen support $(p=0.001)$ were higher in the HLT group. Calculated creatinine clearance (calculated using the Cockroft-Gault formula [20]) was also higher in the HLT group $(p=0.02)$, whereas ischaemia time was longer in the BSLT group $(p<0.001)$. There were also more diabetics $(p=0.07)$ and more patients were receiving hospital treatment at the time of transplantation $(p=0.08)$ in the HLT group. Significant differences in centre preference towards the type of transplantation were noted $(\mathrm{p}<0.001)$. BSLT was carried out at all seven centres, but only three centres performed HLT; one of the largest centres performed only BSLT. In the three centres that performed both procedures, HLT was more common (fig. 2). The model to derive propensity scores from the recipient covariates was well calibrated (lack of fit, $\mathrm{p}=0.64$ ), and showed good discrimination (area under the ROC curve $=0.77$ ).

\section{Survival}

At analysis, 72 CF recipients had died. The actuarial 4-yr survival for the whole cohort was 56\% (95\% confidence interval (CI) 47-63). The median follow-up of survivors was 48 and 35 months in the HLT and BSLT groups, respectively. Unadjusted Kaplan-Meier survival revealed a tendency towards better survival in the BSLT group $(\mathrm{p}=0.09$; log rank test; fig. 3). The 4-yr unadjusted survival for HLT and BSLT groups was 51\% (95\% CI 40-61) and 60\% (95\% CI 46-71), respectively. After adjustment for propensity scores, time on the waiting list, specific recipient factors, ischaemia time and donor factors, there was no significant difference in survival between the two groups (hazard ratio (BSLT versus HLT) $=0.64$; $95 \%$ CI $0.35-1.18 ; p=0.15)$. When the analysis was also adjusted for centre, the risk of death in the HLT group was reduced further (hazard ratio (BSLT versus HLT) $=0.77 ; 95 \%$ CI $0.29-2.06 ; \mathrm{p}=0.60$ ). The proportional-hazards assumption was tenable for both models (test for nonproportionality, $\mathrm{p}=0.42$ and $\mathrm{p}=0.44$, respectively).

\section{Rejection and infection}

The median time to the first detected rejection episode was 22 days (interquartile range (IQR) 11-60 days) for BSLT and 25 days for HLT (IQR 13-263 days). After adjusting for propensity-score quartiles and CMV mismatch, there was no significant difference in the time to first rejection between BSLT and HLT groups (hazard ratio $=0.99 ; 95 \%$ CI $0.65-1.51$; $\mathrm{p}=0.97)$. The proportional-hazards assumption was tenable

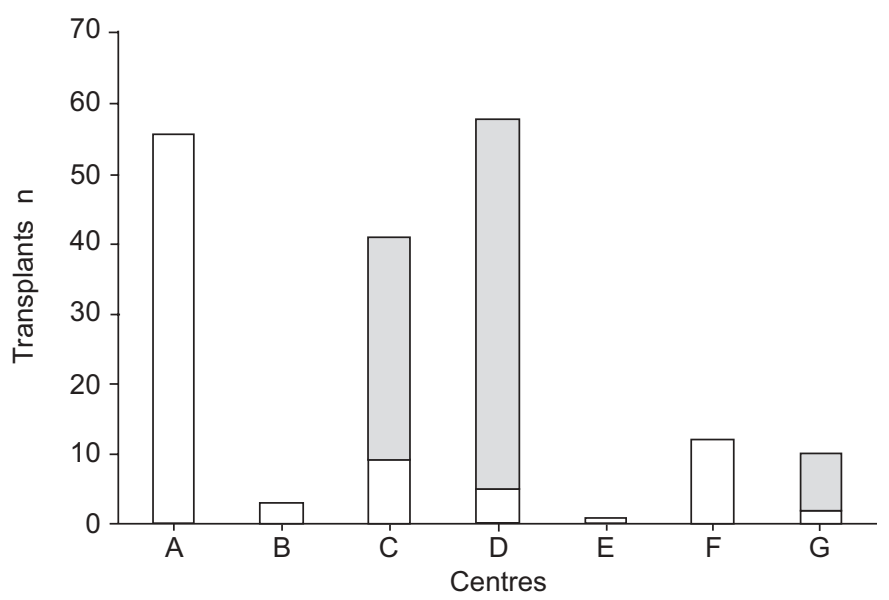

FIGURE 2. Number of bilateral sequential lung $(\square)$ and heart-lung ( $\square$ ) transplantations performed in the centres. 


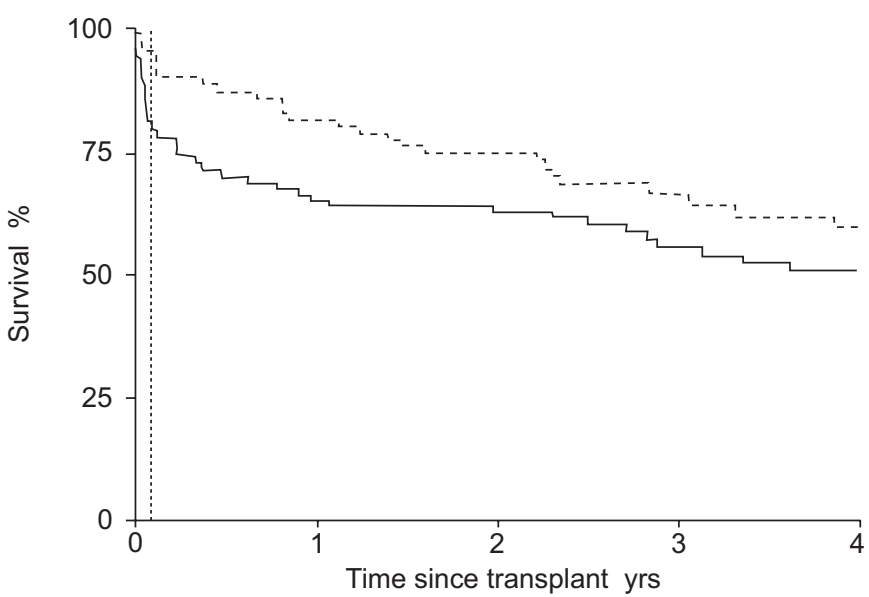

FIGURE 3. Unadjusted Kaplan-Meier survival estimates for bilateral sequential lung (----) and heart-lung $(-)$ transplantation in cystic fibrosis recipients $(p=0.09)$. $\cdots \cdots \cdot 30$ days.

(test for nonproportionality, $\mathrm{p}=0.41$ ). There was no difference in the number of infection episodes between the two types of transplant (incidence rate ratio $=0.79 ; 95 \%$ CI $0.44-1.43$; $\mathrm{p}=0.45)$.

\section{Post-operative FEV 1}

Information on post-operative FEV1 has only been routinely collected since January 2001 and was incomplete. In total, 19 of the 34 HLT survivors at the 4-yr follow-up have had FEV1 recorded (median (IQR) $2.7 \mathrm{~L}(2.13-4.16)$ ) and 17 of the 25 BSLT 4-yr survivors have had their FEV1 recorded (median (IQR) 2.83 L (2.18-3.17)). Pre-operative FEV1 was documented for all but three HLT recipients. At the 4-yr follow-up, the difference between pre-operative and post-operative FEV1 was a median (IQR) of 1.96 L (1.04-2.73) for HLT and 2.03 L (1.582.52) for BSLT. Categorising the 4-yr post-transplant FEV1 values as percentages of the best post-transplant FEV1 values [21] revealed a bronchiolitis obliterans syndrome (BOS) category 0 for all 17 of the available BSLT-recipient data and 15 out of $19(79 \%)$ of the available HLT-recipient data. One HLT recipient was in BOS category 1 , whereas the remaining three were in BOS category 3.

\section{Organ use}

The transplantation of hearts from BSLT donors was compared against the usage of domino hearts from CF recipients; 54 $(61 \%)$ of the 88 hearts from BSLT donors were transplanted, the heart was not retrieved in $34(39 \%)$ donors and the specific reasons for nonretrieval are detailed in table 2. In the HLT group, $76(82 \%)$ domino hearts were used and 17 (18\%) were not used. For seven, this was due to the size of the domino heart, in one case there was no response to a "fast-track" offer and the reason was not recorded for the remaining nine hearts. Survival at 4 yrs for the recipients of hearts from BSLT donors and recipients of domino hearts was $72.6 \%$ (95\% CI 57.3-83.2) and $77.0 \%$ (95\% CI 65.5-85.0), respectively (log rank test, $\mathrm{p}=0.77$ ). The current authors were not able to assess the development of cardiac allograft vasculopathy, because the database was set up to collect a limited number of variables for audit purposes.

\begin{tabular}{ll}
\hline TABLE 2 & $\begin{array}{l}\text { Reasons for nonretrieval of hearts in bilateral } \\
\text { sequential lung donors }\end{array}$ \\
\hline Reasons & \\
\hline Subjects n & 34 \\
Family permission refused & $4(12)$ \\
Donor unsuitable, past history & $2(6)$ \\
Donor unsuitable, size & $2(6)$ \\
No suitable recipients & $5(14)$ \\
Poor organ function & $6(17)$ \\
Inotropes & $3(9)$ \\
Other disease & $1(3)$ \\
Organ damaged & $1(3)$ \\
Cold ischaemia time too long & $1(3)$ \\
Heart retrieved for valves only & $1(3)$ \\
Donor unsuitable, medical reason & $3(9)$ \\
Zone team felt organ not viable & $3(9)$ \\
Other identified cause & $2(6)$ \\
\hline
\end{tabular}

Data are presented as $\mathrm{n}(\%)$, unless otherwise stated. \#: reason unknown.

\section{Waiting time and waiting-list mortality}

A total of 451 adult CF patients (aged $\geqslant 16$ yrs) were registered for either HLT $(n=241)$ or BSLT $(n=210)$ on the waiting list between July 1995 and June 2002. At the time of analysis, 29 remained on the waiting list and 20 had been removed from the list (four patients were subsequently re-registered and went on to have a transplant, four died and the status of the remaining 12 is unknown). In total, 232 patients received transplantation (101 HLT, 119 BSLT, six en bloc double lungs and six bilateral living lobar transplantations). This number exceeds the number included in the main study cohort, as transplants were performed after the end of June 2002. The time to transplant for this cohort differed significantly $(\mathrm{p}<0.001, \log$ rank test) between HLT (median (IQR) 337 days (122-867)) and BSLT (median (IQR) 736 days $(312-1,410)$ ) groups. The majority of patients received the transplant that they were initially registered for; three out of 101 HLT recipients were registered for BSLT and 27 out of 131 BSLT recipients were registered for HLT. One hundred and seventyfour patients died on the waiting list: 101 in the HLT group and 73 in the BSLT group. There was a significant difference in the time to death on the waiting list $(p<0.001, \log$ rank test) between the HLT (median (IQR) 561 days $(207-1,103)$ ) and BSLT (median (IQR) 957 days (379-undefined period)) groups.

\section{DISCUSSION}

Although HARDY et al. [22] performed the first lung transplantation in 1963, it was not until the initial experience with combined HLT in the early 1980s that replacement of lungs was successfully accomplished in humans [23-25]. Techniques of isolated single- and double-lung (DLT) transplantation and BSLT were subsequently developed. CF patients suffer from respiratory failure associated with bilateral lung sepsis and hence, require replacement of both lungs, leading to the necessity of HLT, BSLT or en bloc DLT. Isolated single-lung transplantation and contralateral pneumonectomy for $\mathrm{CF}$ have 
been described, but have only been used in rare circumstances [26]. DLT has been advocated in the past, but concerns about healing led to its discontinuation [14]. DLT was excluded from the current study because of the small number of transplants performed in the study period. BSLT avoids the risk of cardiac allograft vasculopathy, which may be as high as $12 \%$ after combined HLT [27]. The risk of transplanting a denervated heart and its attendant concerns are also avoided [9]. Reoperation rates due to bleeding may be as high as $28 \%$ in HLT [28] and initial results of HLT for CF patients were disappointing in some centres [29], while those achieved by others were more encouraging, with 5-yr survival rates up to $52 \%[11,30]$. Early reports documented a high incidence of airway complications following BSLT, which was not seen in HLT, but the incidence of airway complications in BSLT has decreased subsequently [14]. One of the attractive features of HLT is the potential domino donor heart, which is fully prepared for transplantation and from a living donor. The potential advantage of a domino donor heart over a cadaveric heart has been highlighted in a recent study [31].

In the current study, HLT and BSLT recipients were similar in their pre-transplant characteristics, although HLT recipients received home oxygen support more frequently and had an increased incidence of prior resuscitation. HLT recipients had better creatinine clearance than BSLT recipients. Also, there were more diabetics in the HLT group and proportionally more recipients in this group were receiving hospital treatment at the time of transplant, although this was not statistically significant. Significant centre preferences for one procedure over the other were observed, and this was evaluated by analysing survival with and without an adjustment for centre. A significant reduction in the number of HLT procedures since 2000 was noted in this study, and it is believed that this may be due to a general decrease in transplant activity in the UK, along with changing trends in organ availability and demand.

It was found that survival to 4 yrs, unadjusted for differences in comorbidity between the two groups, tended to favour BSLT. However, when survival was adjusted for comorbidity and donor factors, no significant survival advantage was seen after either BSLT or HLT. Time to the first rejection episode and 4-yr infection-episode rates were compared and were found to be similar in both groups. Information on postoperative FEV1 has only been collected since January 2001, and was similar across the groups, although the data were too few to allow a definitive conclusion to be drawn.

Analysis of the use of hearts from BSLT donors and domino hearts from HLT recipients revealed a higher proportion of hearts being used from domino donors, ameliorating the impact of heart usage in HLT.

Waiting times in the two groups were different in that CF patients who were registered for BSLT waited longer for their transplant and also lived longer on the waiting list. A small number of patients who were registered for HLT went on to receive a BSLT and vice versa, suggesting that HLT and BSLT have been used in a comparable way in the UK. Patients on the waiting list for HLT died significantly earlier than patients waiting for BSLT, despite being on the waiting list for a shorter duration, supporting the view that they were sicker at the time of listing and, hence, at transplantation.

The present study has limitations that would be expected of an observational multicentre study. The type of operation was not randomly assigned. The current authors have attempted to adjust for bias due to differences in risk between the two groups through the use of propensity scores and the inclusion of key donor and recipient factors in the regression models. Regression modelling can never entirely account for group imbalances, and the adjusted estimates may still be subject to some residual confounding. However, such confounding is unlikely to change the conclusion. The data used in the current study was collected as part of a multicentre audit of thoracic organ transplantation, and was not designed specifically to address the choice of operation for CF patients. As a result, the present authors were not able to provide details of cardiac allograft vasculopathy in the domino hearts, although a recent study from one of the centres involved in the audit reported results on this complication [31]. Post-operative management was specific to each centre, was not recorded in detail and, therefore, could not be accounted for in the present study. Nevertheless, the data reflects the outcome of a large unselected and consecutive series of CF patients treated in the UK. Data in the audit are properly validated by means of regular computer validation programs, performed bimonthly, and case-note validation performed biannually, for accuracy and consistency. The possibility that a small difference in the outcome of the two procedures will become apparent when a much larger number of cases have been accrued cannot be excluded.

\section{Conclusion}

The current findings suggest that bilateral sequential lung and heart-lung transplantation achieved similar results in cystic fibrosis patients with respiratory failure once disease severity and comorbidity had been adjusted for. Therefore, the choice of operation may continue to be determined by centre/surgeon preference, and will be influenced by factors such as donor organ availability and whether a domino heart-transplant programme has been established in a centre.

\section{ACKNOWLEDGEMENTS}

The members of the steering group of the UK Cardiothoracic Transplant Audit are as follows: P. Braidley (Northern General Hospital, Sheffield); J.H. Dark (Freeman Hospital, Newcastle); M. Elliott (Great Ormond Street Hospital for Children, London); B. Gutteridge (Representative of National Specialist Commissioning Advisory Group (NSCAG), Dept of Health, London); A. Khaghani (Harefield Hospital, Harefield); J. van der Meulen (Clinical Effectiveness Unit (CEU), The Royal College of Surgeons of England, London); A.J. Murday (Scottish Cardiopulmonary Transplant Unit, Glasgow); J. Wallwork (Papworth Hospital, Papworth); and N. Yonan (Wythenshawe Hospital, Manchester).

The unit data coordinators were as follows: S. Beer, $\mathrm{H}$. Constance, Y. Davenport, J. Hasan, M. Kerr, V. Salter, K. White, and P. Whitmore.

The authors are indebted to the Data Executive at UK Transplant, Bristol, who initially accrue and assimilate the data for analysis by the UK Cardiothoracic Transplant Audit. 


\section{REFERENCES}

1 Cystic Fibrosis Trust. Facts and Figures. http://81.91.109.76/ scope/documentlibrary/12\%20FACTS\%20ABOUT\%20CYSTIC \%20FIBROSIS.pdf. Date last accessed: March 192005.

2 Cystic Fibrosis Foundation. Facts about CF. http:/ / www.cff. org/publications / files/Facts\%20About $\% 20$ CF\%20Fact $\% 20$ Sheet.pdf. Date last accessed: February 192004.

3 Egan TM, Detterbeck FC, Mill MR, et al. Improved results of lung transplantation for patients with cystic fibrosis. $J$ Thorac Cardiovasc Surg 1995; 109: 224-234.

4 Vricella LA, Karamichalis JM, Ahmad S, Robbins RC, Whyte RI, Reitz BA. Lung and heart-lung transplantation in patients with end-stage cystic fibrosis: the Stanford experience. Ann Thorac Surg 2002; 74: 13-17.

5 Egan TM, Detterbeck FC, Mill MR, et al. Long term results of lung transplantation for cystic fibrosis. Eur J Cardiothorac Surg 2002; 22: 602-609.

6 Hodson ME. Cystic Fibrosis. In: Banner NR, Polak JM, Yacoub $\mathrm{MH}$, eds. Lung Transplantation (Post Graduate Medical Science Series). Cambridge, Cambridge University Press, 2003; pp. 71-84.

7 Boucek MM, Edwards LB, Keck BM, et al. The Registry of the International Society for Heart and Lung Transplantation: Sixth Official Pediatric Report-2003. J Heart Lung Transplant 2003; 22: 636-652.

8 Trulock EP, Edwards LB, Taylor DO, et al. The Registry of the International Society for Heart and Lung Transplantation: Twentieth Official adult lung and heartlung transplant report-2003. J Heart Lung Transplant 2003; 22: 625-635.

9 Barlow CW, Robbins RC, Moon MR, Akindipe O, Theodore J, Reitz BA. Heart-lung versus double-lung transplantation for suppurative lung disease. J Thorac Cardiovasc Surg 2000; 119: 466-476.

10 de Leval MR, Smyth R, Whitehead B, et al. Heart and lung transplantation for terminal cystic fibrosis. A 4 1/2-year experience. J Thorac Cardiovasc Surg 1991; 101: 633-641.

11 Yacoub MH, Banner NR, Khaghani A, et al. Heartlung transplantation for cystic fibrosis and subsequent domino heart transplantation. J Heart Transplant 1990; 9: 459-466.

12 Madden BP, Hodson ME, Tsang V, Radley-Smith R, Khaghani A, Yacoub MH. Intermediate-term results of heart-lung transplantation for cystic fibrosis. Lancet 1992; 339: 1583-1587.

13 Massard G, Shennib H, Metras D, et al. Double-lung transplantation in mechanically ventilated patients with cystic fibrosis. Ann Thorac Surg 1993; 55: 1087-1091.

14 Shennib H, Noirclerc M, Ernst P, et al. Double-lung transplantation for cystic fibrosis. The Cystic Fibrosis Transplant Study Group. Ann Thorac Surg 1992; 54: 27-31.

15 Anyanwu AC, Rogers CA, Murday AJ. Where are we today with pulmonary transplantation? Current results from a national cohort. UK Cardiothoracic Transplant
Audit Steering Group. Transpl Int 2000; 13: Suppl. 1 245-246.

16 D'Agostino RB. Propensity score methods for bias reduction in comparison of a treatment to a non-randomised control group. Stat Med 1998; 17: 2265-2281.

17 Blackstone EH. Comparing apples and oranges. J Thorac Cardiovasc Surg 2002; 123: 8-15.

18 Tanner JM, Whitehouse RH, Takaishi M. Standards from birth to maturity for height, weight, height velocity, and weight velocity: British children, 1965. II. Arch Dis Child 1966; 41: 613-635.

19 Cox DR. Regression models and life-tables. J R Stat Soc Ser B 1972; 34: 187-220.

20 Cockcroft DW, Gault MH. Prediction of creatinine clearance from serum creatinine. Nephron 1976; 16: 31-41.

21 Estenne MF, Maurer JR, Boehler A, et al. Bronchiolitis obliterans syndrome 2001: an update of the diagnostic criteria. J Heart Lung Transplant 2002; 21: 297-310.

22 Hardy JD, Webb WR, Dalton ML, Walker GR. Lung homotransplantation in man. JAMA 1963; 186: 1065-1074.

23 Radley-Smith R, Khaghani A, Banner NR. Combined heart and lung transplantation. In: Banner NR, Polak JM, Yacoub $\mathrm{MH}$, eds. Lung Transplantation (Post Graduate Science Series). Cambridge, Cambridge University Press, 2003; pp. 141-157.

24 Reitz BA, Wallwork JL, Hunt SA, et al. Heart-lung transplantation: successful therapy for patients with pulmonary vascular disease. $N$ Engl J Med 1982; 306: 557-564.

25 Patterson GA. Indications. Unilateral, bilateral, heart-lung, and lobar transplant procedures. Clin Chest Med 1997; 18: 225-230.

26 Dark JH. Single and bilateral lung transplantation. In: Banner NR, Polak JM, Yacoub $\mathrm{MH}$, eds. Lung Transplantation (Post Graduate Science Series). Cambridge, Cambridge University Press, 2003; pp. 132140 .

27 Dawkins KD, Jamieson SW, Hunt SA, et al. Long-term results, hemodynamics, and complications after combined heart and lung transplantation. Circulation 1985; 71: 919-926.

28 Sharples LD, Scott JP, Dennis C, et al. Risk factors for survival following combined heart-lung transplantation. The first 100 patients. Transplantation 1994; 57: 218-223.

29 Frist WH, Fox MD, Campbell PW, Fiel SB, Loyd JE, Merrill WH. Cystic fibrosis treated with heart-lung transplantation: North American results. Transplant Proc 1991; 23: 1205-1206.

30 Yacoub MH, Gyi K, Khaghani A, et al. Analysis of 10-year experience with heart-lung transplantation for cystic fibrosis. Transplant Proc 1997; 29: 632.

31 Anyanwu AC, Banner NR, Mitchell AG, Khaghani A, Yacoub MH. Low incidence and severity of transplantassociated coronary artery disease in heart transplants from live donors. J Heart Lung Transplant 2003; 22: 281-286. 